\title{
Experimental Philosophy
}

\author{
Jordan Kiper, Stephen Stich, H. Clark Barrett, \& Edouard Machery
}

Kiper, J., Stich, S., Barrett, H.C., \& Machery, E. (in press). Experimental philosophy. In D. Ludwig, I. Koskinen, Z. Mncube, L. Poliseli, \& L. Reyes-Garcia (Eds.), Global Epistemologies and Philosophies of Science. New York, NY: Routledge.

Acknowledgments: This publication was made possible through the support of a grant from the John Templeton Foundation. The opinions expressed in this publication are those of the author(s) and do not necessarily reflect the views of the John Templeton Foundation.

\footnotetext{
Abstract

Philosophers have argued that some philosophical concepts are universal, but it is increasingly clear that the question of philosophical universals is far from settled, and that far more crosscultural research is necessary. In this chapter, we illustrate the relevance of investigating philosophical concepts and describe results from recent cross-cultural studies in experimental philosophy. We focus on the concept of knowledge and outline an ongoing project, the Geography of Philosophy Project, which empirically investigates the concepts of knowledge, understanding, and wisdom across cultures, languages, religions, and socioeconomic groups. We outline questions for future research on philosophical concepts across cultures, with an aim towards resolving questions about universals and variation in philosophical concepts.
} 


\section{Introduction}

For centuries, thinkers have urged that fundamental philosophical concepts, such as the concepts of knowledge or right and wrong, are universal or at least shared by all rational people (e.g., Plato 1892/375 BCE; Kant, 1998/1781; Foot, 2003). Yet many social scientists, in particular cultural anthropologists (e.g., Boas, 1940), but also continental philosophers such as Foucault (1969) have remained skeptical of these claims. Andriessen and Boom describe "the Confucian concept of knowledge" as follows $(2007,645)$ : "Basic in the Confucian concept of knowledge is the unity of knowledge and action. Knowledge exists in action. Knowledge is not a formal structure of ideas on the level of rational thinking or representation: knowledge unfolds itself in (moral) action." And they quote Eliade (1992) in support of their claim: "Knowledge in its genuine and earnest aspect is action and action in its intelligent and discriminating aspect is knowledge" (quoted in Andriessen \& Boom, 2007, 645). Much is at stake not only philosophically, but also scientifically, if crucial philosophical concepts are indeed cross-culturally universal (Stich, 1990, 2018; Stich \& Tobia, 2016; Machery, 2017). Until recently, compelling empirical evidence about their universality has remained scant. It was not until the early twenty-first century that anthropologists, philosophers, historians, and linguists began to accumulate data suggesting that what it means to know, and how we as humans come to possess knowledge, may not be the same for all historical periods, cultures, and demographic groups (e.g., Weinberg et al., 2001; Bromhead, 2009; Cohen, 2010; Rheinberger, 2010).

To what extent do people around the world share philosophical concepts? This is an empirical question that cannot be answered by consulting existing ethnographies, surveys, or historical accounts. Most cultural studies prior to the onset of massive cross-cultural studies in the 2010s, which we discuss below, were centered on occasional descriptions of philosophical 
concepts, rather than focused investigations of those concepts. Partly as a response to this gap in the literature, experimental philosophy — a new line of research, led primarily by philosophers, but also involving cultural psychologists and anthropologists-was initiated in the early twenty-first century. Experimental philosophy uses methods from anthropology, cross-cultural psychology, and linguistics to examine philosophical concepts, and thereby address traditional philosophical questions and investigate how people ordinarily think.

In what follows, we highlight some of the results of these empirical studies, which suggest that the question of philosophical universals is far from settled, and that far more cross-cultural research is necessary. To illustrate what is at stake, we will focus in detail on the concept of knowledge, and use it as a case study throughout this chapter.

Our discussion proceeds as follows. We begin by questioning the assumption that philosophical concepts are universal. We then explain why assessing this assumption is so important. After considering these, it will become clearer why experimental philosophy is increasingly focusing on cross-cultural projects, as illustrated by experimental philosophy research on the concept of knowledge. Finally, we outline an ambitious project, the Geography of Philosophy Project, which empirically investigates the concepts of knowledge, understanding, and wisdom across cultures, languages, religions, and socioeconomic groups.

\section{Are there Universal Philosophical Concepts?}

Some leading figures in Western philosophy have held that one or another important philosophical concept is universal. According to Kant's discussion of human nature in Anthropology from a Pragmatic Point of View, a concept of justice is part of the "animal nature" that is shared by all human beings (Kant, 1996, 176): "It appears as if a certain concept of justice (which applies to 
external freedom) evolves together with the animal nature; consequently, it is not something that is gradually learned." Similar views can be found among more recent philosophers. A good example is a forthcoming article by leading philosophers and cognitive scientists, which argues that the concept of knowledge is a basic representation, shared by monkeys, apes, and human beings on a par with universal representational capacities such as the capacity to represent magnitudes (Phillips et al., in press): "a capacity for knowledge representation [that has] ended up being one that is cognitively basic."

Well-known social scientists have likewise maintained that important philosophical concepts are held by people in all cultures (e.g., Wierzbicka, 1992, 1996; Mikhail, 2011). To illustrate, in his study of magical thinking, Mauss held that the concept of mana was universal, despite being rarely lexicalized, as Leacock explains (1954, 62): "For example, in Mauss' study of magic, which will be discussed later, magical practices were studied in a number of societies and were found in a number of cases to be associated with the concept of mana. It was therefore assumed that the concept of mana was universal, and that all magical practices were ultimately based on this concept." Mauss (1938) similarly believed that the concept of a self, while actively denied by Buddhists and other philosophical traditions, is nevertheless an innate mental category, and thus a universal. More recently, Clyde Kluckhohn has defended the universality of some moral concepts $(1955,672)$ : "Every culture has a concept of murder, distinguishing this from execution, killing in war, and other 'justifiable homicides.' The notions of incest and other regulations upon sexual behavior, the prohibitions upon untruth under defined circumstances, of restitution and reciprocity, of mutual obligations between parents and children - these and many other moral concepts are altogether universal." 
Skepticism over these claims has nonetheless persisted among ethnographers, historians, and linguists whose work focuses on the analysis of specific cultures (e.g., Boas, 1940; Geertz, 1993). Among ethnographers, there is great skepticism about the existence of many sorts of universals. Emotions, for instance, are claimed to be so complex when expressed in a particular culture that only a detailed narrative could do justice to their relative meaning (Beatty, 2013); a fortiori concepts of emotions are bound to be culturally local (Lutz, 1982, 1988). Likewise, the historical genealogies of Foucault (1997) suggest to many scholars that what we might have taken to be universal concepts are in fact socially constructed and importantly different in particular historical contexts. For example, contrary to Mauss, Foucault claims that the concept of self is constructed by various self-oriented practices that vary across periods and cultures (Foucault, 1969). Numerous linguistic anthropologists have similarly claimed that subtle cultural and linguistic differences in the meanings of words challenges the universality of many supposedly universal concepts (e.g., Everett, 2005). If these skeptics are right, concepts of interest to Western philosophers are very unlikely to be identical across all or even most cultures.

An alternative middle ground to these views is that there may be a universal core to many philosophical concepts that is elaborated in different ways in distinct cultures (e.g., Atran, 1998 on folk biological concepts; Lillard, 1998 on folk-psychological concepts). Machery et al. (2017a) have, for instance, speculated that the culture-specific concepts of knowledge, expressed by the words usually taken to translate "to know that," may well share a common core, while varying in other respects (see also Hannon, 2015; for discussion, see Wierzbicka, 2018).

\section{What is At Stake?}


Much is at stake in whether philosophical concepts are universal. For one thing, discovering the universality of some concepts will tell us much about the mind and just how malleable our minds are (Machery \& Faucher, 2020). The issue is also central for determining which philosophical projects are worth pursuing. Additionally, the relativity of certain concepts is of practical importance for cross-cultural communication and cooperation in science, politics, and law.

\subsection{Cross-Cultural Communication}

Cross-cultural communication is an important practical issue affected by the debate about the universality of philosophical concepts. Deep differences in philosophical concepts across cultures would surely pose a challenge to communication across cultural divides (e.g., Andriessen \& Boom, 2007 on the concept of knowledge). The challenge will be even greater if many of these conceptual differences are covert - that is, hidden by what appears to be a shared vocabulary or misleading traditional translations. On the other hand, central philosophical concepts that are shared across cultures, would be important foundations on which to build cross-cultural understanding.

\subsection{Malleability of Mind}

The existence of universal philosophically important concepts would demand an explanation, raising a host of questions: Is their universality a product of some constraints imposed by our cognitive architecture? If so, are these concepts adaptations or rather spandrels? In the former case, are they still adaptive? Alternatively, these philosophical concepts may be either so obvious or useful that they have been invented and re-invented all over the world and transmitted by cultural transmission. 


\subsection{What Philosophical Projects are Worthwhile?}

Variation in philosophical concepts across cultures or other demographics would matter philosophically because it would raise questions about the significance of century-long research tradition in Western philosophy. The details of this argument are intricate (Stich, 1990; Machery, 2017, pp. 126-48), but the gist of the argument is simple: Epistemology, for instance, would simply be an exercise in understanding the way Westerners talk about "knowledge," and it is entirely unclear why we should value this inquiry. ${ }^{1}$ Focusing on epistemic concepts such as the concepts of knowledge and justification, Stich put the point as follows (1990, 20): "The analytic epistemologist proposes to evaluate these differing cognitive processes by explicating our intuitive notions of cognitive evaluation [e.g., the concept of knowledge], and then exploring which inferential processes fall most comfortably within the extension of those notions. But these intuitive notions of cognitive evaluation are themselves local cultural products, and there is no reason to think that they won't exhibit just as much intercultural and interpersonal variation as the cognitive processes that they evaluate. In light of this, it is hard to see why most people would care very much whether a system of cognitive processes falls within the extension of some ordinary notion of epistemic evaluation-why, for example, they would care whether their reasoning falls within the boundaries of the intuitive notion of rationality - unless of course there is some reason to think that falling within the extension of one of these concepts correlates with something else we do care about."

\section{Experimental Philosophy}

1 "Westerners" refers to the people born and raised in Western Europe, the USA, Canada, New Zealand, and Australia. 
Whether philosophical concepts are universal or vary across cultures as well as the extent and manner to which they vary are empirical questions that cannot be answered from the armchair. To answer them, a new philosophical tradition emerged at the beginning of the twenty-first century known as experimental philosophy. Experimental philosophy examines, among other things, whether and how philosophical concepts vary across groups, including cultures. It relies on the methods of empirical sciences, primarily psychology, but also anthropology and, increasingly, linguistics and neuroscience (e.g., Knobe \& Nichols, 2008, 2014; Machery \& O’Neill, 2014; Sytsma \& Livengood, 2015; Sytsma \& Buckwalter, 2016; Fischer \& Curtis, 2019). It often borrows methods from the social sciences such as free listing tasks, questionnaires, and responses to vignettes (often modeling vignettes on famous philosophical thought experiments).

Frequently, participants are presented with a vignette describing an imaginary situation. For instance, in Machery et al.'s (2017a) study on the concept of knowledge participants in Brazil, the USA, India, and Japan were presented with the following vignette:

Paul Jones was worried because it was 10 pm and his wife Mary was not home from work yet. Usually she is home by $6 \mathrm{pm}$. He tried her cell phone but just kept getting her voicemail. Starting to worry that something might have happened to her, he decided to call some local hospitals to ask whether any patient by the name of "Mary Jones" had been admitted that evening. At the University Hospital, the person who answered his call confirmed that someone by that name had been admitted with major but not life-threatening injuries following a car crash. Paul grabbed his coat and rushed out to drive to University hospital. As it turned out, the patient at University Hospital was not Paul's wife, but another 
woman with the same name. In fact, Paul's wife had a heart attack as she was leaving work, and was at that moment receiving treatment in Metropolitan Hospital, a few miles away. Did Paul know that his wife was in a hospital?

In addition to this target question, participants were asked additional comprehension questions, and a pair of questions designed to determine whether they thought Paul's belief was justified and whether they thought Paul thought he knew, but didn't. Responses were analyzed statistically to look for patterns. Using vignettes such as this, and varying the information in the vignette, allows experimental philosophers to identify the cues that influence or fail to influence the application of concepts such as the concept of knowledge (Machery et al., 2017a).

A handful of philosophers began examining the universality of philosophical concepts in recent decades, providing evidence suggesting that variation may exist among and across populations. In particular, variation was reported between Western and East Asian students (Weinberg et al., 2001; Machery et al., 2004), genders (e.g., Buckwalter \& Stich, 2014), and personality characteristics such as introversion and extroversion (Feltz \& Cokely, 2009). These initial findings provided tentative evidence that long-standing assumptions in philosophy about the universally of concepts may not be warranted, and they have led to intense, but fruitful empirical and philosophical debates (Machery et al., 2017a, b; Adleberg et al., 2015; Nagel, 2012; Stich, 2013).

Since the onset of these studies, the literature on the universality of philosophical concepts has grown increasingly sophisticated and rich, and we have no space here to review it in any detail (for an overview, see Stich \& Machery, ms). For sake of brevity, we will continue to focus on the concept of knowledge (see also Mizumoto et al., 2018, 2020a). 
An important aspect of the concept of knowledge, according to many philosophers, is the idea that some forms of luck are incompatible with knowing something: One does not know that $p$ when one acquires a belief that $p$ by luck even if that belief is true. In his famous paper, Gettier (1963) proposed a pair of cases in which, Gettier maintained, the protagonist did not have knowledge despite having a belief that was not only true, but also justified, although acquired by luck. The vignette presented above illustrates the basic structure of a Gettier case: Paul Jones has a true, justified belief that his wife is in a hospital. Most philosophers shared Gettier's verdict about these cases, and a large literature offering additional "Gettier cases" grew out of Gettier's paper in order to characterize the concept of knowledge (Hetherington \& Hetherington, 2010). Just about all of this work was done by English speaking philosophers whose cultural background is European. In one of the earliest experimental-philosophy studies, Weinberg and colleagues (2001) reported evidence that most East Asians and South Asians did not share Gettier's verdict; unlike most Westerners, and the overwhelming majority of philosophers, they judge that protagonists in Gettier cases did have knowledge. Yet, this study was relatively limited in terms of participants, and was in need of replication. Follow-up studies have failed to find any cultural variation in people' judgment about the Gettier case (e.g., Seyedsayamdost, 2015; Kim and Yuan, 2015), but they too are limited, examining few participants and a small number of cultures. Machery et al. (2017a, b) conducted the first large cross-cultural studies about lay people's reaction to Gettier cases: They found that across cultures, most people are like philosophers in being sensitive to the incompatibility of knowing something and luck. In this case, philosophers' judgment about knowledge is in line with those of lay peoples across cultures (but see Starmans and Friedman, 2020), although the sample of cultures examined remains limited. 
Many philosophers have argued that knowledge ascription is sensitive to what is at staketo how costly it would be for the agent to have a false belief (Stanley, 2005): the higher the stakes, the more stringent the criteria for the ascription of knowledge. Here, too, Rose and colleagues (2019) found that people ascribe knowledge similarly across cultures and languages: Across 19 sites, 16 countries, and 14 languages, stakes barely matter for knowledge ascription. It is noteworthy that in this case philosophers' judgment about knowledge turned out to be widely different from lay people's since many epistemologists have asserted that stakes influence lay ascription of knowledge.

Other studies compare participants in two or three countries. Some philosophers have argued that asserting something is only permissible when one knows it. Turri and Park (2018) have shown that like American participants, Korean participants judge that one should not assert something that is false because one lacks knowledge in this case. Yuan and Kim (ms) have presented evidence that just like American participants, Korean and Chinese participants are less likely to ascribe knowledge when the evidence is based on textual information about the probability of error than when it is perceptual (holding the risk of error constant), are influenced by moral factors when they ascribe knowledge, and are willing to ascribe knowledge to someone while denying her the relevant belief.

In the previous examples, little variation was found across cultures and languages, but other cases show that cultures and languages influence how people ascribe knowledge and other epistemic concepts (e.g., see Chimakonam \& Ogbonnaya; Ito; Liu \& King; Winther; Yen). Philosophers often begin their discussion of knowing something by contrasting it to merely believing it or to believing it with justification. This starting point surely reflects the fact that "knowing that" and "believing that" are two distinct expressions in English as in other languages 
commonly spoken by philosophers. While common, this linguistic distinction is not universal, and some languages such as Cofán, a language spoken in northeast Ecuador and southern Colombia, do not distinguish lexically knowing and believing something (Chartrand et al., $\mathrm{ms}^{2}$ ). Speakers of these languages may of course still distinguish the concepts expressed in English by "knowing that" and "believing that," but it may also be the case that they don't. Be that as it may, it is dubious that philosophers would start their discussion of knowing by contrasting knowing and believing that if they spoke one of these languages. Based on the semantics of "knowing how" in English, Stanley and Williamson (2001) have argued that all knowledge-how reduces to propositional knowledge, but critics have been quick to note that other languages such as French lexicalize know-how and propositional knowledge quite differently (Rumfit, 2003).

Cross-cultural experimental studies have also begun identifying variation in knowledge ascription. Philosophers have claimed that people refrain from ascribing knowledge to someone who has a true belief when the possibility that this belief could be false is salient, a phenomenon philosophers call "skeptical pressure." One of the most influential ideas in epistemology, the context-sensitivity of knowledge, is meant to address the impact of skeptical pressure on knowledge ascription (e.g., Lewis, 1996). In two experiments Waterman and colleagues (2018) have recently shown that participants in India, China, and the USA were all sensitive to skeptical pressures, but Chinese and Americans were much more sensitive to the presence or absence of a possibility of error than Indians. Perhaps, then, it was a mistake to make so much of the contextsensitivity of knowledge ascription in English when building a theory of knowledge. Mizumoto (2018) also notes that "to know" corresponds to two distinct verbs in Japanese, and provides evidence that they are used differently, raising questions about the generalizability of observations

${ }^{2}$ https://clics.clld.org/edges/1410-1890 
about the use of "know" in English (see also Mizumoto et al., 2020b on the expression of "to know how" in Japanese).

In any case, most of the studies we have mentioned have serious limitations. Most studies involve only two or three cultural groups, and even the largest studies included very few smallscale societies (Machery et al., 2017b; Rose et al., 2019). Further, participants are often undergraduates, who may share a common cultural background and many shared assumptions from being raised in the same educational system. Much remains to be known, then, about whether, how, and why epistemic concepts vary across languages and cultures, and while some important notions in epistemology — particularly, the incompatibility of knowledge and some form of luckhave been found across cultures, others may reflect the peculiarities of epistemic languages in English and a few other languages.

\section{The Geography of Philosophy Project}

Though the work that has been done so far provides a promising beginning, much more crosscultural experimental research in philosophy is necessary (as is the case in the cognitive sciences more broadly, see Barrett, 2020). Philosophers and anthropologists are increasingly using both large and small cross-cultural studies that employ experimental methods to focus on the universality or variability of particular phenomena. These have included studies of communication styles based on individualism and collectivism (e.g., Hofstede, 2011), perspectives on cooperation and sociality (e.g., Henrich \& Ensminger, 2014), and aspects of cognition such as judgments about intentions (e.g., Barrett et al., 2016). Inspired by such projects, Machery, Stich, and Barrett assembled an international team of philosophers, psychologists, linguists, and anthropologists working on five continents, to collect data about three important philosophical concepts: the 
concepts of knowledge, wisdom, and understanding (see also Hall et al., in prep on the concept of knowledge). The resulting project, the Geography of Philosophy (www.geographyofphilosophy.com), plans to compare students and non-students across cultures, religions, and socio-economic groups. Small scale societies are included among the cultures we are surveying.

The Geography of Philosophy Project examines some of the topics discussed earlier-e.g., whether luck prevents the ascription of knowledge, the influence of stakes on knowledge ascription, whether knowledge is a norm of assertion - and others (e.g., how do people judged to be wise ask for advice or what dimensions distinguish people judged to be wise from those judged to be unwise). An important feature of the project is its interdisciplinarity. In addition to philosophers and psychologists the project includes linguists, anthropologists, economists and scholars in cultural studies. People in all of these fields can play a crucial role in identifying existing scholarship and in formulating and testing novel hypotheses about similarities and differences in the concepts of knowledge, understanding, and wisdom.

Interpreting the variation of philosophical concepts across languages and cultures requires linguistic expertise. As an illustration, in Machery et al. (2017a), a puzzling pattern emerged in the responses of Bengali speaking participants in Kolkata (Calcutta). Bengali speakers were outliers compared to others, insofar as they appeared to ascribe knowledge even when a true belief was acquired by luck, at least for some formulations of the questions participants were asked. However, when Bengali speaking scholars were consulted, the explanation became evident. The words commonly used to translate "to know" in Bengali ("jáná") and in Sanskrit "jñáa" (the verbal root of the Bengali word) are used somewhat differently from "to know" in English. In particular, the distinction between "to believe" and "to know" is not always retained when "jáná" or "jñá" are 
used. Thus, "jáná” may in fact express two rather different concepts in Bengali, one of which is closer to the concept expressed in English by "know" and the other closer to the concept expressed in English by “believe." Inspired by this experience, the Geography of Philosophy Project involves a detailed study of the epistemic vocabulary used in the languages of the project.

Finally, cultural anthropologists traditionally immerse themselves within a culture, using distinctive methods to understand other people's lifeways. By incorporating those techniques, and working with cultural anthropologists, experimental philosophers can grasp unexpected understandings of philosophical concepts. An interesting example is reported by cultural anthropologists exploring the concept of knowledge related to shamanism in the western Amazon, where "knowledge" has a bodily component that can be passed from shaman to shaman (Homan, 2019; see also Kiper, 2019). The Geography of Philosophy Project includes qualitative methods, including interviews and focus groups, to complement the usual experimental and quantitative methods commonly used in experimental philosophy.

\section{Conclusion}

Experimental philosophy has yielded remarkable data that have opened new avenues of research and demonstrated the likelihood that philosophical concepts vary cross-culturally in at least some important respects. As we attempted to show in this chapter, empirical data challenge traditional assumptions about widely shared concepts. Accordingly, taking variation seriously entails more cross-cultural studies and greater interdisciplinarity in the field. 


\section{References}

Adleberg, T., Thompson, M., \& Nahmias, E. (2015). Do men and women have different philosophical intuitions? Further data. Philosophical Psychology, 28(5), 615-641.

Andriessen, D., \& Boom, M. V. D. (2007). East is East, and West is West, and (n) ever its intellectual capital shall meet. Journal of Intellectual Capital, 8(4), 641-652.

Atran, S. (1998). Folk biology and the anthropology of science: Cognitive universals and cultural particulars. Behavioral and brain sciences, 21(4), 547-569.

Barrett, H. C. (2020). Towards a cognitive science of the human: Cross-cultural Approaches and their urgency. Trends in Cognitive Sciences, 24, 620-638.

Barrett, C., Bolyanatz, A., Crittenden, A., Fessler, D., Fitzpatrick, S., Gurven, M., Henrich, J., Kanovsky, M., Kushnik, G., Pisor, A., Scelza, B., Stich, S., Rueden, C.V., Zhao, W., \& Laurence, S. (2016). Small-scale societies exhibit fundamental variation in the role of intentions in moral judgment. Proceedings of the National Academy of Sciences, 113(17), 4688-4693.

Beatty, A.B. (2013). Current emotion research in anthropology: Reporting the field. Emotion Review, 5(4), 414-422.

Boas, F. (1940). Race, language, and culture. Chicago: University of Chicago Press.

Bromhead, H. (2009). The Reign of Truth and Faith: Epistemic Expressions in 16th and 17th Century English. Berlin: Mouton de Gruyter.

Buckwalter, W., \& Stich, S. (2014). Gender and philosophical intuition, in J. Knobe \& S. Nichols (Eds.), Experimental philosophy, volume 2 (pp. 307-346). New York: Oxford University Press.

Chartrand L., Barr, K., Vindrola, F., Allen, C., and Machery, E. (ms). Unboxing universality and variation: the distribution of epistemic concepts across culture. 
Cohen, E. (2010). Anthropology of knowledge. Journal of the Royal Anthropological Institute, 16, S193-S192.

Eliade, M. (1992). Neo-Confucianism. In M. Eliade (Ed.), Encyclopedia of Religion. Macmillan Reference Books.

Everett, D. (2005). Cultural constraints on grammar and cognition in Pirahã. Current Anthropology, 46(4), 621-646.

Feltz, A., \& Cokely, E.T. (2009). Do judgments about freedom and responsibility depend on who you are? Personality differences in intuitions about compatibilism and incompatibilism. Consciousness and Cognition, 18(1), 342-350.

Fischer, E., \& Curtis, M. (Eds.). (2019). Methodological advances in experimental philosophy. London: Bloomsbury Publishing.

Foucault, M. (1969). The archaeology of knowledge. Paris: Éditions Gallimard.

Foucault, M. (1997). Essential works of Foucault, 1954-1984. Vol 1., Ethics: subjectivity and truth (ed. P. Rabinow). New York: Penguin.

Geertz, C. (1993). Local knowledge. London: Fontana.

Hall, B. F., et al. (in prep.). Registered replication report: Turri, Buckwalter, and Blouw (2015). https://psyarxiv.com/zeux9/.

Hannon, M. (2015). The universal core of knowledge. Synthese, 192(3), 769-786.

Henrich, J., \& Ensminger, J. (2014). Experimenting with social norms. Russell Sage Foundation Press.

Hetherington, S., \& Hetherington, S. C. (Eds.). (2018). The Gettier problem. Cambridge University Press. 
Hofstede, G. (2011). Dimensionalizing cultures: The Hofstede model in context. Online readings in psychology and culture, 2(1).

Homan, J. (2019). Routes to knowledge in the upper Amazon. Go Philosophy: Official Blog for the Geography of Philosophy Project, October 3, 2019. << https://go-philosophy.com/routes-toknowledge/ >>

Kant, I. (1996). Anthropology from a Pragmatic Point of View (trans. V. L. Dowdell). Carbondale: Southern Illinois University Press.

Kiper, J. (2019). An anthropological perspective, part 1. Go Philosophy: Official Blog for the Geography of Philosophy Project, July 3, 2019. << https://go-philosophy.com/?s=Kiper >>

Kluckhohn, C. (1955). Ethical Relativity: sic et non. The Journal of Philosophy, 52(23), 663-677.

Knobe, J., \& Nichols, S. (Eds.) (2008) Experimental philosophy. London: Oxford University Press.

Knobe, J., \& Nichols, S. (Eds.) (2014) Experimental philosophy, volume 2. London: Oxford University Press.

Leacock, S. (1954). The ethnological work of Marcel Mauss. American Anthropologist, 56, 58-73.

Lewis, D. K. (1996). Elusive knowledge. Australasian Journal of Philosophy, 74(4), 549-567.

Lillard, A. (1998). Ethnopsychologies: cultural variations in theories of mind. Psychological bulletin, 123, 3-32.

Machery, E. (2017). Philosophy within its proper bounds. Oxford: Oxford University Press.

Machery, E., \& Faucher, L. (2020). The folk concept of race. In T. Marques and A. Wikforss (Eds.), Shifting concepts: The philosophy and psychology of conceptual variability (pp. 167-189). Oxford University Press. 
Machery, E., \& O'Neill, E. (Eds.). (2014). Current controversies in experimental philosophy. New York: Routledge.

Machery, E., Mallon, R., Nichols, S., \& Stich, S. P. (2004). Semantics, cross-cultural style. Cognition, 92, B1-12.

Machery, E., et al. (2017a). Gettier Across Cultures. Nous, 51(3), 645-664.

Machery, E., et al. (2017b). The Gettier intuition from South America to Asia. Journal of Indian Council of Philosophical Research, 34(3), 517-541.

Mauss, M. (1938). Une catégorie de l'esprit humain: La notion de personne, celle de 'moi' un plan de travail (A category of the human spirit: The idea of the person, the idea of 'self' a plan). Journal of the Royal Anthropological Institute, 68, 263-281.

Mikhail, J. (2011). Elements of moral cognition: Rawls' linguistic analogy and the cognitive science of moral and legal judgment. New York: Cambridge University Press.

Mizumoto, M. (2018). “Know” and its Japanese counterparts. In M. Mizumoto, S. Stich, and E. McCready (Eds.), Epistemology for the Rest of the World (pp. 77-120). New York: Oxford University Press.

Mizumoto, M., Stich, S., \& McCready, E. (Eds.) (2018). Epistemology for the Rest of the World. New York: Oxford University Press.

Mizumoto, M., Ganeri, J., \& Goddard, C. (Eds.) (2020). Ethno-epistemology: New directions for global epistemology. New York: Routledge.

Mizumoto, M., Tsugita, S., \& Izumi, Y. (2020). Knowing how and two knowledge verbs in Japanese. In M. Mizumoto, J. Ganeri, and C. Goddard (Eds.), Ethno-epistemology: New directions for global epistemology (pp. 43-76). New York: Routledge. 
Nagel, J. (2012). Intuitions and experiments: A defense of the case method in epistemology. Philosophy and Phenomenological Research, 85(3), 495-527.

Nahmias, E., Morris, S.G., Nadelhoffer, T., \& Turner, J. (2006). Is incompatibilism intuitive?

Philosophy and Phenomenological Research, 73(1), 28-53.

Phillips, J., Buckwalter, W., Cushman, F., Friedman, O., Martin, A., Turri, J., Santos, L., \& Knobe, J. (in press). Knowledge before belief. Behavioral and Brain Sciences.

Rheinberger, H.-J. (2010). On historicizing epistemology: an essay. Stanford: Stanford University Press.

Rose, D., et al. (2019). Nothing at stake in knowledge. Noûs, 53(1), 224-247.

Rumfitt, I. (2003). Savoir faire. The Journal of Philosophy, 100, 158-66.

Seyedsayamdost, H. (2015). On normativity and epistemic intuitions: Failures of replication. Episteme, 12(1), 95-116.

Stanley, J. (2005). Knowledge and practical interests. Philosophy and Phenomenological Research, 75, 168-172.

Stanley, J., \& Williamson, T. (2001). Knowing how. Journal of Philosophy, 98, 411-444.

Starmans, C., \& Friedman, O. (2020). Expert or Esoteric? Philosophers Attribute Knowledge Differently Than All Other Academics. Cognitive Science, 44(7), e12850.

Stich, S. P. (1990). The fragmentation of reason: Preface to a pragmatic theory of cognitive evaluation. Cambridge, MA: MIT Press.

Stich, S. P. (2013). Do different groups have different epistemic intuitions? A Reply to Jennifer Nagel. Philosophy and Phenomenological Research, 87(1), 151-178.

Stanley, J., \& Williamson, T. (2001). Knowing how. The Journal of Philosophy, 98(8), 411-444. 
Stich, S. P. (2018). Knowledge, intuition and culture. In J. Proust \& M. Fortier (Eds.), Metacognitive Diversity: An Interdisciplinary Approach (pp. 381-394). Oxford: Oxford University Press.

Stich, S. P., \& Machery, E. (ms). Demographic differences in philosophical intuition: A reply to Joshua Knobe.

Stich, S. P., \& Tobia, K. (2016). Experimental philosophy and the philosophical tradition. In W. Buckwalter and J. Sytsma (Eds), A Companion to Experimental Philosophy (pp. 5-21). New York and Oxford: Wiley Blackwell.

Sytsma, J., \& Buckwalter, W. (Eds.). (2016). A companion to experimental philosophy. Malden: John Wiley \& Sons.

Sytsma, J., \& Livengood, J. (2015). The theory and practice of experimental philosophy. Peterborough: Broadview Press.

Waterman, J., Gonnerman, C., Yan, K., \& Alexander, J. (2018). Knowledge, certainty, and skepticism. In M. Mizumoto, S. P. Stich, and E. McCready (Eds.), Epistemology for the Rest of the World (pp. 187-214). New York: Oxford University Press.

Weinberg, J.M., Nichols, S. P., \& Stich, S. (2001). Normativity and epistemic intuitions. Philosophical Topics, 29, 429-460.

Wierzbicka, A. (1992). Semantics, culture, and cognition: Universal human concepts in culturespecific configurations. New York: Oxford University Press.

Wierzbicka, A. (1996). Semantics: Primes and universals. New York: Oxford University Press.

Wierzbicka, A. (2018). I know. In M. Mizumoto, S. P. Stich, and E. McCready (Eds.), Epistemology for the Rest of the World (pp. 216-249). New York: Oxford University Press. 